Effect of Ce Promoter on Non-oxidative Dehydrogenation of Propane over

\title{
Commercial $\mathrm{Cr} / \mathrm{Al}_{2} \mathrm{O}_{3}$ Catalyst
}

Yaliu Zhang, ${ }^{\dagger}$, Shuang Yang, ${ }^{\ddagger}$ Jichang Lu, ${ }^{\ddagger}$ Yi Mei, ${ }^{\dagger}, \S$ Dedong $\mathrm{He}^{*}, \dagger, \S$ and Yongming Luo $^{*}$,

$\dagger$ Faculty of Chemical Engineering, Kunming University of Science and Technology, Kunming 650500, P. R. China.

$¥$ Faculty of Environmental Science and Engineering, Kunming University of Science and Technology, Kunming 650500, P. R. China.

$\S$ Yunnan Provincial Key Laboratory of Energy Saving in Phosphorus Chemical Engineering and New Phosphorus Materials, Kunming 650500, P. R. China.

Corresponding author

*E-mail: dedong.he@qq.com (D.H.).

*E-mail: environcatalysis222@yahoo.com (Y.L.). 

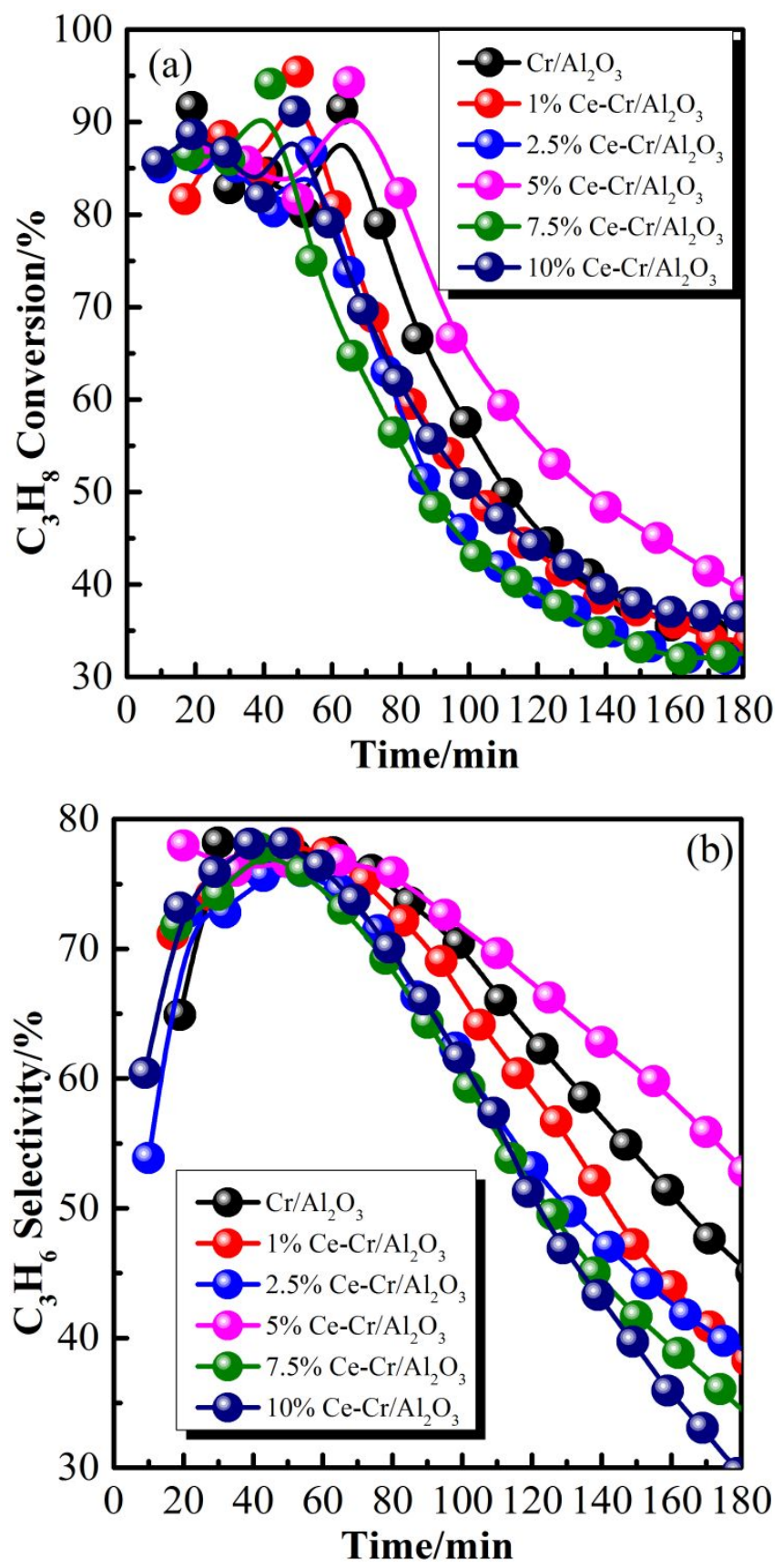

Figure S1. Reactivity of Ce-Cr/ $\mathrm{Al}_{2} \mathrm{O}_{3}$ with different Ce loadings: (a) $\mathrm{C}_{3} \mathrm{H}_{8}$ conversion;

(b) $\mathrm{C}_{3} \mathrm{H}_{6}$ selectivity

Different Ce loadings of $\mathrm{Ce}-\mathrm{Cr} / \mathrm{Al}_{2} \mathrm{O}_{3}$ catalysts were optimized before experiment tests. The results show that the $\mathrm{Ce}-\mathrm{Cr} / \mathrm{Al}_{2} \mathrm{O}_{3}$ catalyst with $5 \mathrm{wt} . \%$ Ce loading has the best activity. 

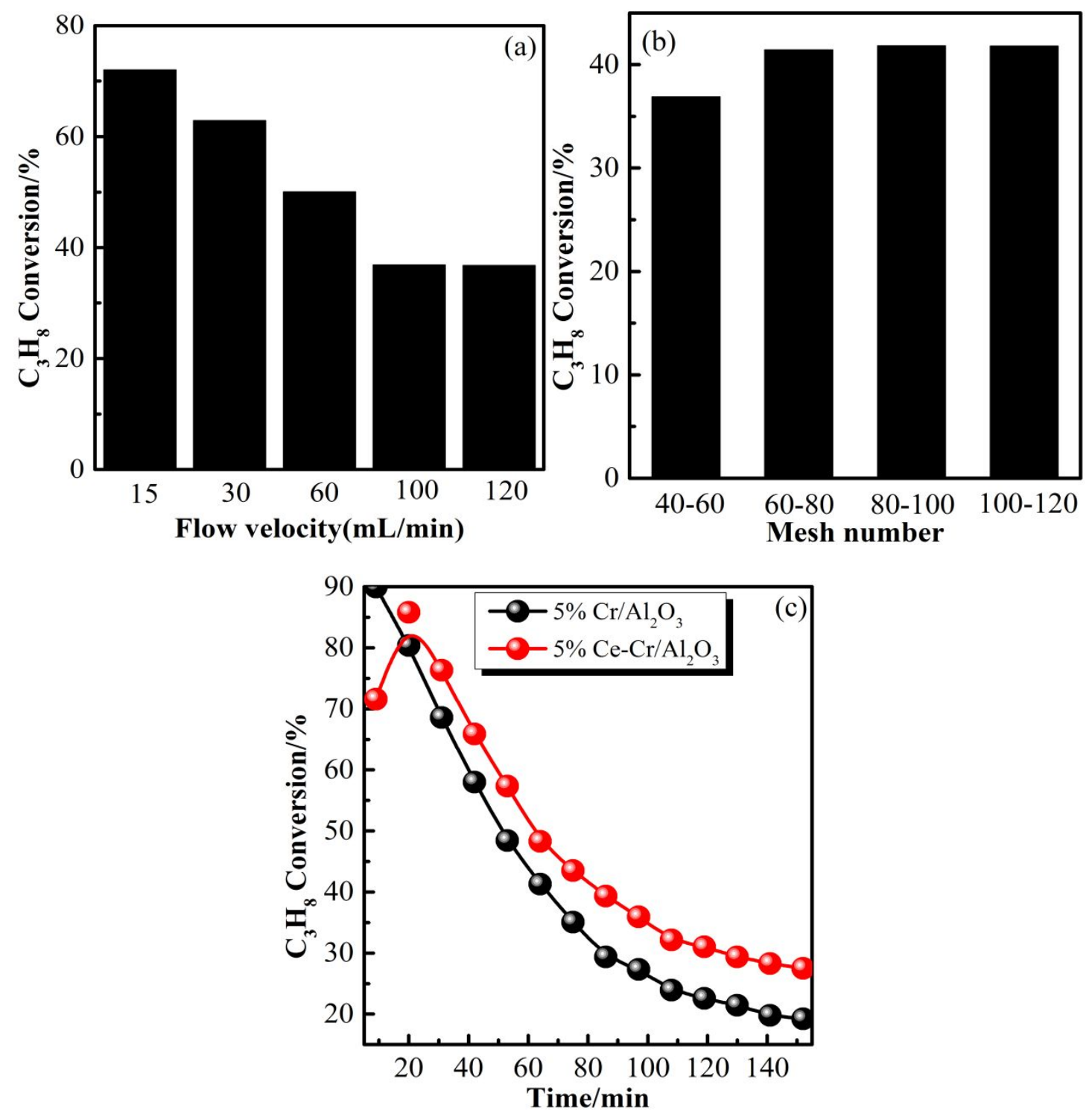

Figure S2. The conversion of $\mathrm{C}_{3} \mathrm{H}_{8}$ over $\mathrm{Cr} / \mathrm{Al}_{2} \mathrm{O}_{3}$ as a function of flow velocity with a fixed mesh of 40-60 (a), a mesh number catalysts with a fixed flow velocity of 100 $\mathrm{mL} / \mathrm{min}(\mathrm{b})$ and the conversion of $\mathrm{C}_{3} \mathrm{H}_{8}$ as a function of $\mathrm{Cr} / \mathrm{Al}_{2} \mathrm{O}_{3}$ and $\mathrm{Ce}-\mathrm{Cr} / \mathrm{Al}_{2} \mathrm{O}_{3}$

(c).

The elimination of gas diffusion influence before activity test is considered. It is accepted that increasing gas velocity is an effective way to eliminate external mass transfer resistance, while decreasing particles size is considered to eliminate internal mass transfer resistance. Firstly, the experimental test for the conversion of $\mathrm{C}_{3} \mathrm{H}_{8}$ as a function of gas velocity $(15,30,60,100,120 \mathrm{~mL} / \mathrm{min})$ was conducted over $5 \%$ 
$\mathrm{Cr} / \mathrm{Al}_{2} \mathrm{O}_{3}$ samples with a fixed particle size (40-60 mesh). The results are shown in Figure S2(a). It is found that the conversions of $\mathrm{C}_{3} \mathrm{H}_{8}$ are independent of the gas velocity when the gas flow rate is higher than $100 \mathrm{~mL} / \mathrm{min}$, indicating the absence of external mass transfer effect at this high velocity. Then, the reaction on different average sizes (40-60, 60-80, 80-100,100-120 mesh, i.e., 250-380, 180-250, 150-180, $120-150 \mu \mathrm{m}$ ) of catalyst was studied over $5 \% \mathrm{Cr} / \mathrm{Al}_{2} \mathrm{O}_{3}$ sample with a fixed flow velocity of $100 \mathrm{~mL} / \mathrm{min}$. The results are displayed in Figure S2(b). It is observed that the catalysts with particle size larger than 80-100 mesh show no intraparticle diffusion limitation. Therefore, in the following studies, the total flow rate was kept constant at $100 \mathrm{~mL} / \mathrm{min}$, whereas the catalyst diameters were kept within the above-mentioned range of 80-100 mesh. The activity results are displayed in Figure S2(c). Obviously, the conversion of the catalyst modified with $\mathrm{Ce}$ is better than that of the unmodified one.

Table S1 TOF estimates for $\mathrm{Cr} / \mathrm{Al}_{2} \mathrm{O}_{3}$ and $\mathrm{Ce}-\mathrm{Cr} / \mathrm{Al}_{2} \mathrm{O}_{3}$ catalysts

\begin{tabular}{|c|c|}
\hline Catalyst & TOF $10^{-4}\left(\mathrm{~s}^{-1}\right)$ \\
\hline $5 \% \mathrm{Cr} / \mathrm{Al}_{2} \mathrm{O}_{3}$ & 1.74 \\
\hline $5 \% \mathrm{Ce}-\mathrm{Cr} / \mathrm{Al}_{2} \mathrm{O}_{3}$ & 2.08 \\
\hline
\end{tabular}

The calculated TOFs for these catalyst are listed in Table S1. It is seen that adding Ce into this catalyst system obviously increases the TOF of the catalyst, which suggests that $\mathrm{Ce}$ addition can enhance the catalytic performance. 

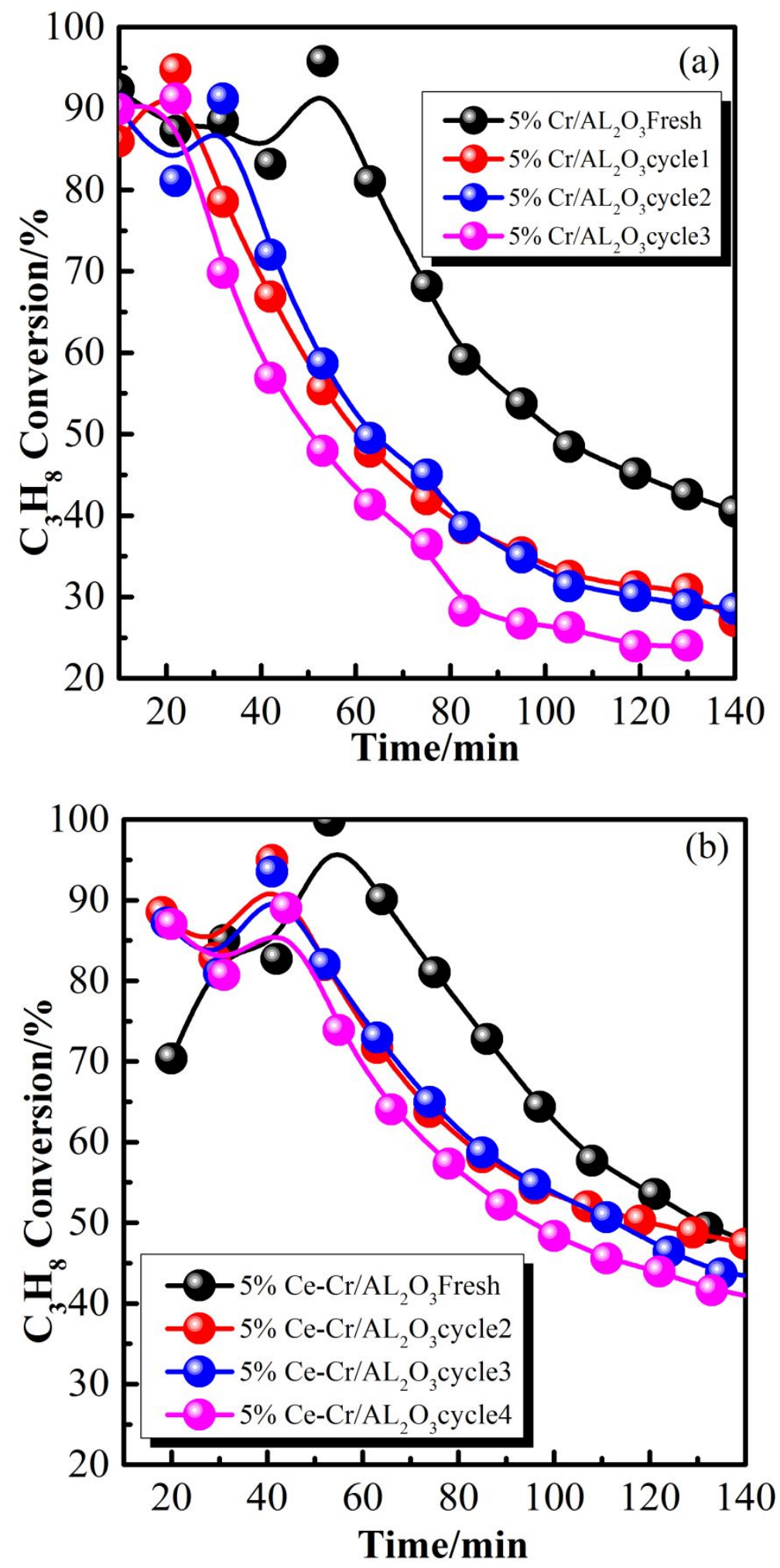

Figure S3. Reactivity comparison between (a) $5 \% \mathrm{Cr} / \mathrm{Al}_{2} \mathrm{O}_{3}$ and (b) $5 \% \mathrm{Ce}-\mathrm{Cr} / \mathrm{Al}_{2} \mathrm{O}_{3}$ with four regeneration cycles. 

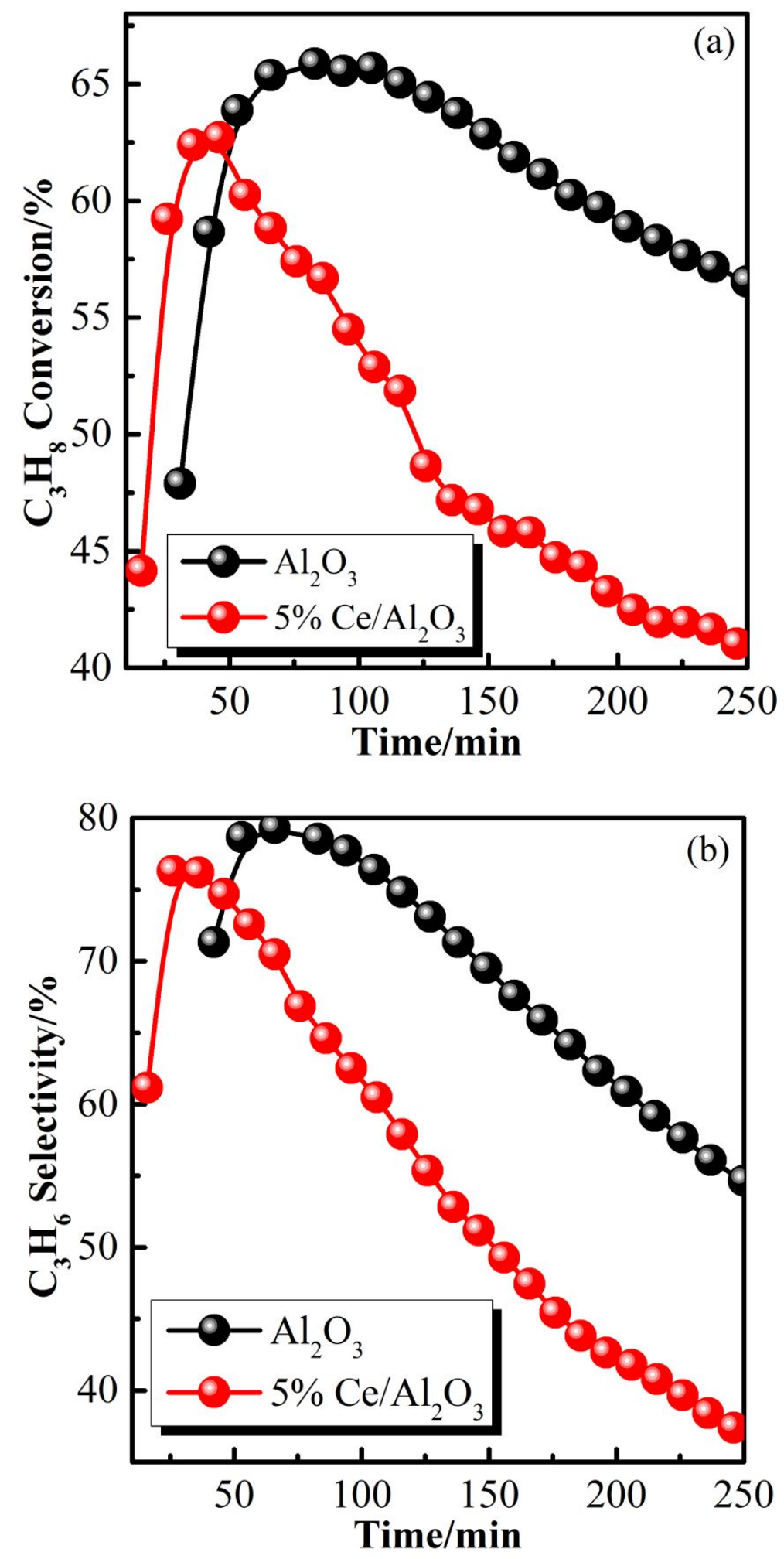

Figure S4. $\mathrm{C}_{3} \mathrm{H}_{8}$ conversion (a) and $\mathrm{C}_{3} \mathrm{H}_{6}$ selectivity (b) as a function of reaction time over pure $\mathrm{Al}_{2} \mathrm{O}_{3}$ and $5 \% \mathrm{Ce} / \mathrm{Al}_{2} \mathrm{O}_{3}$. 


\section{$\mathrm{Cr}(\mathrm{VI})$}

$\mathrm{Cr}(\mathrm{III})$

Isolated $\mathrm{Cr}(\mathrm{VI})$

Figure S5 Schematic representation of the presence of different chromium species

The general knowledge is that low $\mathrm{Cr}$ loadings contribute to good dispersion of $\mathrm{Cr}$ species, and consequently, mononuclear $\mathrm{Cr}(\mathrm{VI})$ as well as some $\mathrm{Cr}(\mathrm{III})$ species with coordinative vacancies are obtained (J. Catal. 261 (2009) 116-128; J. Catal. 293 (2012) 67-750). However, high Cr loadings cause the formation of inactive Cr(III) species, as clusters and/or crystalline $\mathrm{Cr}_{2} \mathrm{O}_{3}$, due to the consumption of silica surface hydroxyl groups. In fact, at high $\mathrm{Cr}$ loading, not all the $\mathrm{Cr}(\mathrm{VI})$ species are expectantly converted to inactive $\mathrm{Cr}$ (III) species. Instead, some of the unexpected $\mathrm{Cr}(\mathrm{VI})$ species, as isolated $\mathrm{Cr}(\mathrm{VI})$, which can not been anchored by the exhausted surface hydroxyl groups are found (as seen in Figure S5). 

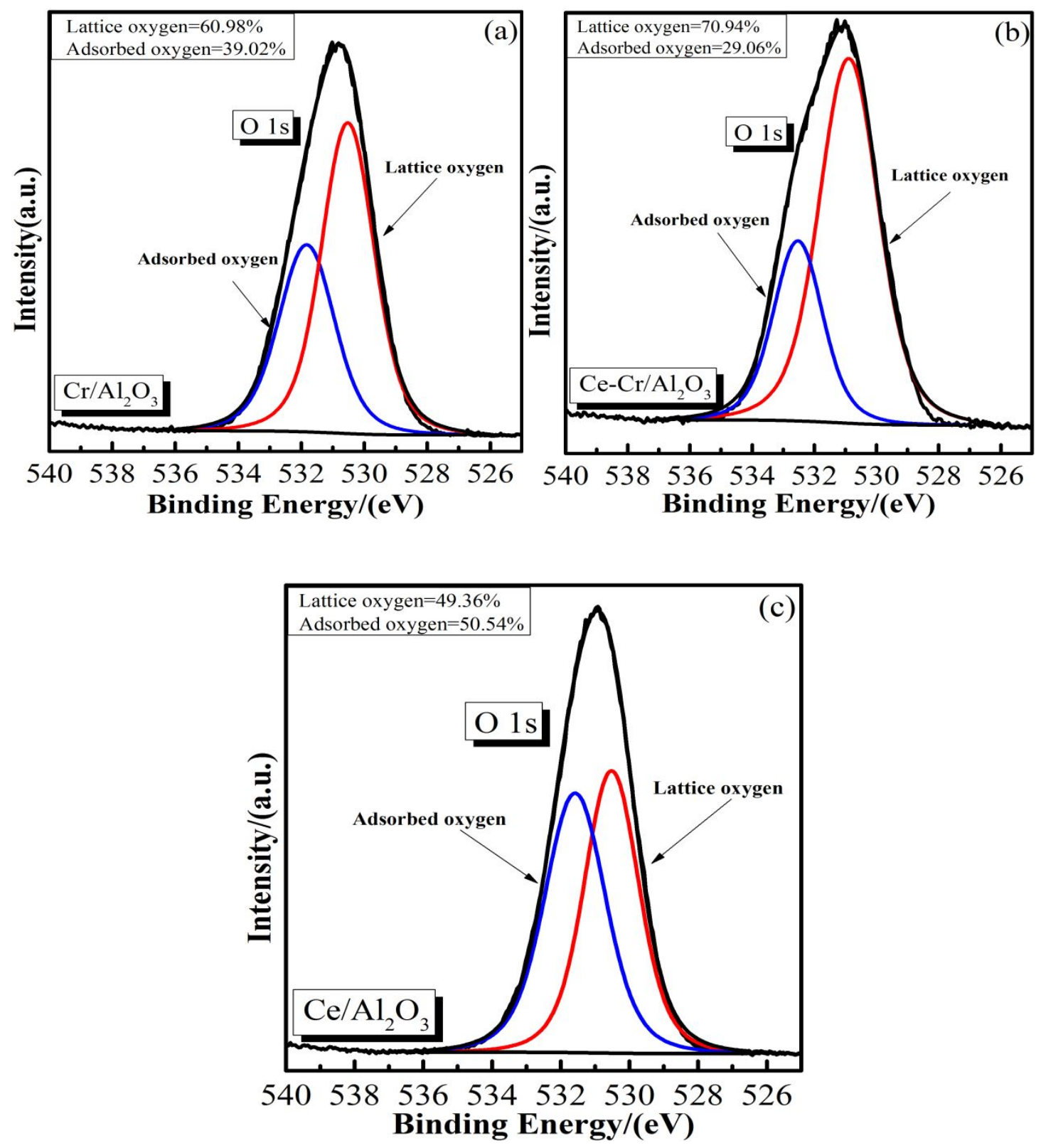

Figure S6. O 1s XPS spectra of the investigated catalysts. 


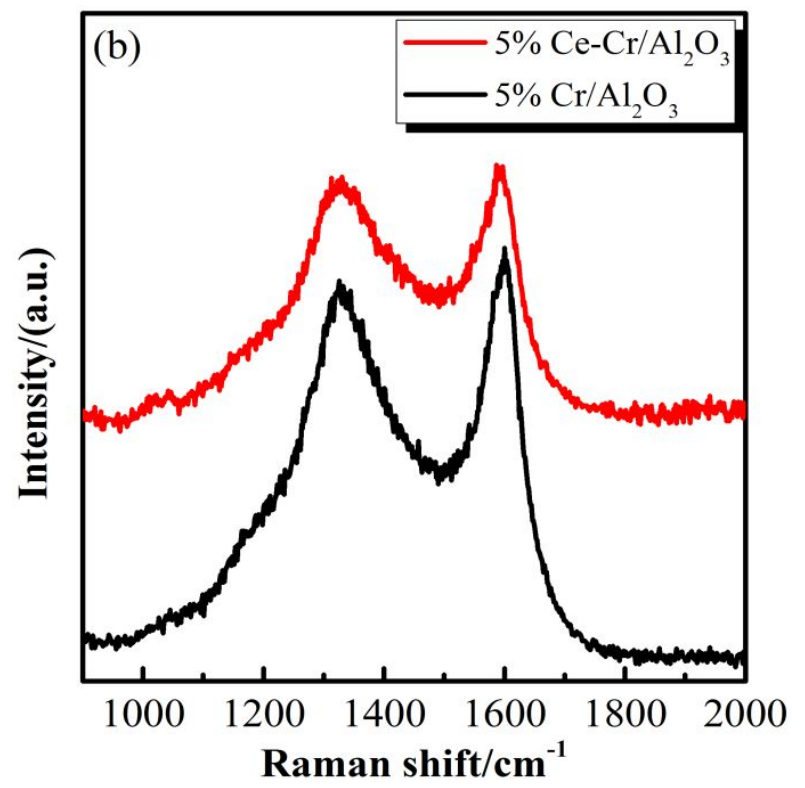

Figure S7. Raman of spent catalysts on $5 \% \mathrm{Cr} / \mathrm{Al}_{2} \mathrm{O}_{3}$ and $5 \% \mathrm{Ce}-\mathrm{Cr} / \mathrm{Al}_{2} \mathrm{O}_{3}$ 